\title{
Quantifying micro-environmental variation in tropical rainforest understory at landscape scale by combining airborne LiDAR scanning and a sensor network
}

\author{
Blaise Tymen $^{1}$ - Grégoire Vincent ${ }^{2}$ - Elodie A. Courtois ${ }^{3,4}$ • Julien Heurtebize ${ }^{2}$. \\ Jean Dauzat $^{2} \cdot$ Isabelle Marechaux $^{1}$ • Jérôme Chave ${ }^{1}$
}

Received: 29 September 2016 / Accepted: 10 March 2017 / Published online: 14 April 2017

(C) INRA and Springer-Verlag France 2017

\begin{abstract}
- Key message We combined aerial LiDAR and ground sensors to map the spatial variation in micro-environmental variables of the tropical forest understory. We show that these metrics depend on forest type and proximity to canopy gaps. Our study has implications for the study of natural forest regeneration.

- Context Light impacts seedling dynamics and animals, either directly or through their effect on air temperature and relative humidity. However, the micro-environment of tropical forest understories is heterogeneous.
\end{abstract}

Handling Editor: Aaron R Weiskittel

Contribution of the co-authors BT, GV, EC and JC designed the study, analysed the data and wrote the paper. JH, JD and GV realised the informatics tool for LPI modelling. BT and EC contributed to acquire the field data. All authors provided input on draft manuscripts.

Electronic supplementary material The online version of this article (doi:10.1007/s13595-017-0628-z) contains supplementary material, which is available to authorized users.

Blaise Tymen

blaise.tymen@gmail.com

Grégoire Vincent

gregoire.vincent@ird.fr

Elodie A. Courtois

courtoiselodie@gmail.com

Julien Heurtebize

julienhtbe@gmail.com

Jean Dauzat

jean.dauzat@cirad.fr

Isabelle Marechaux

isabelle.mj.marechaux@gmail.com
- Aims We explored whether aerial laser scanning (LiDAR) can describe short-scale micro-environmental variables. We also studied the determinants of their spatial and intra-annual variation.

- Methods We used a small-footprint LiDAR coverage combined with data obtained from 47 environmental sensors monitoring continuously understory light, moisture and temperature during 1 year over the area. We developed and tested two models relating micro-environmental conditions to LiDAR metrics.

- Results We found that a volume-based model predicts empirical light fluxes better than a model based on the proportion of the LiDAR signal reaching the ground. Understory field sensors measured an average daily light flux between 2.9 and $4.7 \%$ of full sunlight. Relative seasonal variation was comparable in the understory and in clearings. In canopy gaps, light flux was 4.3 times higher, maximal temperature $15 \%$ higher and minimal relative humidity $25 \%$ lower than in the forest understory. We found consistent micro-environmental differences among forest types.

- Conclusions LiDAR coverage improves the fine-scale description of micro-environmental variables of tropical forest

Jérôme Chave

jerome.chave@univ-tlse3.fr

1 Laboratoire Evolution et Diversité Biologique UMR 5174, CNRS, Université Paul Sabatier, 118 route de Narbonne, 31062 Toulouse, France

2 IRD, UMR AMAP, TA A-51/PS1, Bd de la Lironde, 34398 Montpellier, Cedex 5, France

3 Laboratoire Ecologie, évolution, interactions des systèmes amazoniens (LEEISA), Université de Guyane, CNRS, IFREMER, 97300 Cayenne, France

4 Department of Biology, Centre of Excellence PLECO (Plant and Vegetation Ecology), University of Antwerp, Universiteitsplein 1, 2610 Wilrijk, Belgium 
understories. This opens avenues for modelling the distribution and dynamics of animal and plant populations.

Keywords French Guiana $\cdot$ Light $\cdot$ Nouragues station · Plant dynamics $\cdot$ Temperature $\cdot$ Relative humidity

\section{Introduction}

Solar irradiance and spectral composition of understory light are both critical for a range of biological processes, from forest regeneration (Ackerly and Bazzaz 1995; Montgomery and Chazdon 2002; Valladares 2003; Palomaki et al. 2006), to signalling among animals (Endler 1993; Regan et al. 2001). Light is critical to seed germination (Baskin and Baskin 2001; Willis et al. 2014) and seedling and sapling growth within tropical forests (Tinoco-Ojanguren and Pearcy 1995; Baraloto and Goldberg 2004; Palomaki et al. 2006).

Greater light irradiance on the ground also implies increased ground-level air temperature, as predicted by energy balance models (Monteith and Unsworth 2013), and air temperature is expected to bear on heterotrophic respiration processes in the rainforest soil (Salinas et al. 2011). Higher rates of litter decomposition and a faster proliferation of micro-organisms are expected as temperature increases. Higher ground temperature also leads to an increased water evaporation and thus affects both soil and air moisture (Marthews et al. 2008).

Tropical forest canopies absorb or reflect most of direct sunlight, and on average, ground-level light typically represents 1 to $3 \%$ of the above-canopy intensity (Chazdon and Fetcher 1984; Montgomery and Chazdon 2001). Canopy gaps caused by branch or tree falls result in ephemeral and localised, but intense, increases in local irradiance in the understory (Chazdon and Pearcy 1991; Smith et al. 1992; Engelbrecht and Herz 2001). As a result, light availability at ground level is heterogeneous in both time and space (Canham et al. 1994; Nicotra et al. 1999; Montgomery and Chazdon 2001). It is controlled by the geometry of the canopy (Capers and Chazdon 2004), e.g. stem density is a weak predictor of light availability (Montgomery and Chazdon 2001).

Recent advances in remote sensing provide new opportunities for the landscape-scale assessment of forest structure. Small-footprint aerial laser scanning, or LiDAR, provides fine-grained (i.e. $1 \mathrm{~m}^{2}$ ) information on the structure and heterogeneity of forest canopies (Lefsky et al. 2002). On the ground, environmental sensors have also been significantly improved in the past years (Le Galliard et al. 2012). They can now be deployed to measure environmental variables at many points in space and during long periods of time. Previous studies have sought to quantify leaf area index (LAI) in tropical forest using large-footprint LiDAR (Tang et al. 2012) or in temperate forests (Parker et al. 2001; Lee et al. 2009; Mücke et al. 2011; Bode et al. 2014; Peng et al. 2014). Here, we seek to infer the fine-grained variability in understory light intensity by combining small-footprint LiDAR and an environmental sensor network in a natural mixed species lowland Neotropical forest in French Guiana.

We quantify the spatial and temporal variation in key forest understory environmental variables. Specifically, we aim to answer the following three questions. (1) How do metrics derived from airborne LiDAR perform in the prediction of ground-level temperature, relative humidity and local irradiance? (2) What are the variations of micro-environment between different forest types and how do they vary in and around canopy gaps? (3) What are the differences in irradiance, temperature and relative humidity between dry and wet season and do canopy characteristics impact on these differences?

\section{Material and methods}

\subsection{Study site}

We selected a study zone of $5.4 \mathrm{~km}^{2}$ within the old-growth tropical moist forest centred around the Inselberg Camp of the Nouragues Ecological Research Station in French Guiana (Latitude: $4^{\circ} 04^{\prime} 27.986^{\prime \prime} \mathrm{N}$, Longitude: $52^{\circ} 40^{\prime} 45.107^{\prime \prime} \mathrm{W}$ ). Hills and plateaus reaching $250 \mathrm{~m}$ asl alternate with $60-100 \mathrm{~m}$ elevation valleys. A 450-m asl granitic outcrop (inselberg) dominates the area. Annual rainfall is typical of moist tropical forests (average of $2861 \mathrm{~mm}$ year ${ }^{-1}$ on the1992-2012 period) with a two-month dry season (precipitation below $100 \mathrm{~mm} \mathrm{month}^{-1}$ ) in September and October and a shorter one in February or March (Fig. S1 in Online resources). Five types of vegetation can be distinguished in our study zone: high forest, low forest at the margin of the inselberg, low and sparse vegetation on the inselberg, liana-infested forest and periodically flooded forest (Fig. 1). Over 1700 angiosperm species are recorded in the Natural Reserve (Sabatier and Prévost 1990; van der Meer and Bongers 1996).

For this study, after removing the areas containing the campsite and the inselberg, gaps were defined following Brokaw's definition as areas larger than $20 \mathrm{~m}^{2}$ with a canopy height lower than $2 \mathrm{~m}$ (Brokaw 1982). Within the zone of interest, 81 gaps were detected across forest types. Microenvironmental conditions in these gaps were compared with that in buffer zones around them irrespective of the type of surrounding vegetation.

\subsection{LiDAR acquisition}

In March 2012, one aerial laser scanning (LiDAR) acquisition was conducted by the private company ALTOA (http://www. altoa.fr/) over $24 \mathrm{~km}^{2}$ of old-growth forest on the Nouragues Research Station. A portable Riegl laser rangefinder (LMSQ $560,200 \mathrm{kHz}, 1.5 \mu \mathrm{m}$ wavelength laser pulses) was flown on 

interest (adapted from RéjouMéchain et al. 2015). The different forest types were determined using field inventory and ALS-derived information on canopy height topography. Position of light, temperature and relative humidity sensors are marked by red stars
Fig. 1 Map of the zone of

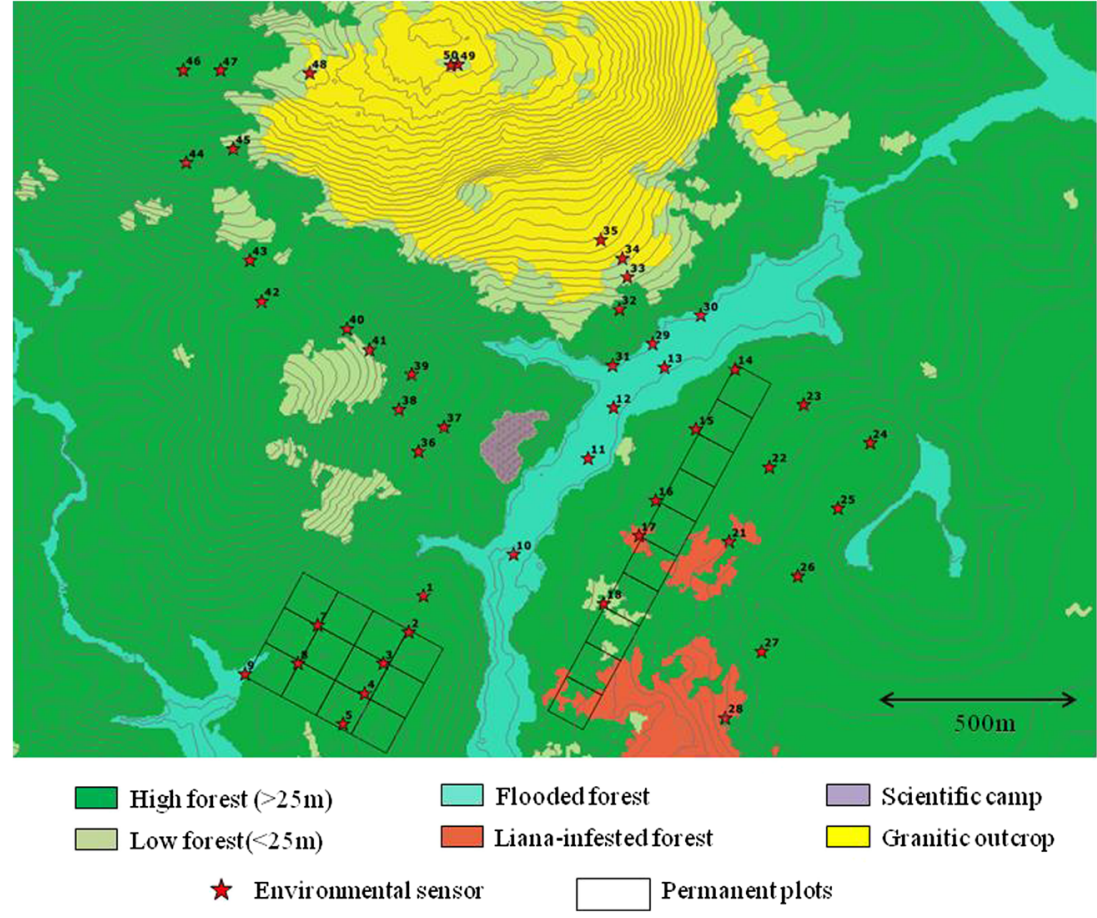

a Britten-Norman Islander (BN2) aircraft at ca. $400 \mathrm{~m}$ above the ground at about $45 \mathrm{~m} \mathrm{~s}^{-1}$. The average laser pulse density was ca. 12 pulse $\mathrm{m}^{-2}$, the scanning angle ranged between $-23^{\circ}$ and $+23^{\circ}$ from vertical and the beam divergence was 0.5 mrad, resulting in a footprint of $0.2 \mathrm{~m}$. Registration of multiple returns led to a mean density of $20 \mathrm{pt} \mathrm{m}^{-2}$ in the zone of interest with a mean spacing of $0.23 \mathrm{~m}$. Two dual-frequency GPS receivers coupled to an inertial navigation system allowed a sub-decimetre differential positioning.

Ground points were filtered with the 'Ground' routine of TerraScan (TerraSolid, Helsinki), average ground points density was $0.77 \mathrm{~m}^{-2}$ with $1.14 \mathrm{~m}$ average spacing. A $1-\mathrm{m}$ resolution digital elevation model (DEM) was constructed using the las2dem function of LAStools software (Insenburg).

\subsection{Light flux modelling}

We used LiDAR signal intensity to approximate canopy transmittance to the whole solar radiation. The backscatter signal is split into as many echoes as the laser beam encounters reflective surfaces (provided they are large enough). Post-processing of full-waveform LiDAR yields not only the location of the echoes but also the energy backscattered by each reflective surface (Wagner et al. 2006). Assuming that the reflectance of the canopy elements is similar across the forest and that the reflected energy does not depend on the laser incident angle (Fig. S3 in Online resources), backscattered energy should be proportional to the scattering cross-section of each surface. We thus weighted LiDAR returns based on their rank and the total number of returns in the pulse they belong to. Weighting was based on the average relative energy associated to each return in the vegetation (Table S1 in Online resources).

We considered transmittance derived from LiDAR and obtained from sub-vertical sampling to be representative of the canopy transmittance in all directions hence considering that transmittance is isotropic. This is equivalent to considering that foliage elements are small, distributed randomly and with a spherical angle distribution (Monteith and Unsworth 2013).

\subsection{Multidirectional light penetration index}

For taking full advantage of LiDAR 3D information, we divided space into cubic cells (voxels). The Beer-Lambert law stipulates that light transmission for each beam exiting a cell should comply with the following equation:

$I_{\text {Out }}=I_{\text {Ent }} \times \exp (-\alpha \times l)$

with $I_{\text {Out }}$ and $I_{\text {Ent }}$, the light intensity entering and exiting the cell, respectively, $\alpha$ the extinction coefficient and 1 the length of the optical path through the cell. Considering multiple incident light beams with different trajectories, the transmittance of a particular cell $j$ normalised by the mean optical path length $l_{\text {mean }}$ is therefore approximated by

$T_{j}=\exp \left(-a_{j}\right)=\left(\frac{I_{\mathrm{Out}, j}}{I_{\mathrm{Ent}, j}}\right)^{-l_{\text {mean }}}$

Thus, the transmittance of each voxel $j$ can be measured by estimating the ratio between the inbound energy and the outbound energy for every beam crossing the voxel $j$ as: 
$\ln \left(\mathrm{T}_{j}\right)=\frac{1}{\frac{1}{n} \sum_{i}^{n} l_{i}} \times \ln \left(\frac{\sum_{i}^{n} \mathrm{PFOut}_{i} \times S_{i} \times l_{i}}{\sum_{i}^{n} \mathrm{PFEnt}_{i} \times S_{i} \times l_{i}}\right)$

where $n$ is the total number of LiDAR beams entering voxel $j$; PFEnt $_{i}$ and PFOut ${ }_{i}$ are respectively the inbound and outbound fractions of the beam energy of pulse $i$ for voxel $j$. They are obtained from the energy fraction of beams after each return (Table $\mathrm{S} 1$ in Online resources). $S_{i}$ is the beam cross-section at voxel centre calculated knowing the distance from source and the beam divergence assuming no fragmentation; $l_{i}$ is the optical path length of the beam $i$ in voxel $j$. The term, $\sum_{i}^{n}$ PFOut $_{i} \times S_{i} \times l_{i}$ represent the volume actually crossed by the beam exiting the considered cell while $\sum_{i}^{n}$ PFEnt $_{i} \times S_{i} \times l_{i}$ is the potential volume sampled by the entering beam. Their ratio approximates the proportion of voxel volume that is travelled without encountering any object.

We also define the plant area density (PAD, the area of vegetation per volume of canopy, in $\mathrm{m}^{2} \mathrm{~m}^{-3}$ ), which is calculated as:

$\mathrm{PAD}=\min \left(\frac{\log _{10}\left(T_{j}\right)}{-0.5}, \mathrm{PAD}_{\max }\right)$

$\mathrm{PAD}_{\text {max }}$ is the maximal admissible value for PAD. PAD max was set to $1 \mathrm{~m}^{2} \mathrm{~m}^{-3}$ here for a $1-\mathrm{m}^{3}$ resolution. Several values were tested without modifying the results qualitatively. In our dataset, around $17 \%$ of canopy voxels were not sampled due to low laser penetration and sampling irregularity. An average of the PAD in a 3D Moore neighbourhood (Balzter et al. 1998) was assigned to unsampled voxels.

Using the 3D information of the PAD in the voxel space, we calculated the light transmitted above ground level by tracing rays in 406 directions corresponding to a split of the sky hemisphere following Dulk's TURTLE model (Dulk 1989; Dauzat et al. 2001, 2007). Light extinction through the forest canopy was then calculated using the Beer-Lambert law: $I_{n}=I_{o} \sum_{\theta}^{406} w_{\theta} \prod_{i}^{\text {nvox }} \exp \left(-0.5 \times \operatorname{PAD}_{i} \times l_{i}\right)$, with $I_{o} w_{\theta}$ the solar radiation in the direction $\theta$ considered for a given period.

Solar position and atmospheric conditions integrated over the year were used to weigh the contribution of each direction to the global light budget. Radiative conditions were characterised by a clearness index kt defined as the ratio of the global irradiance at ground level over the extraterrestrial global solar irradiance above the atmosphere at a month scale (Table S2 in Online resources). Transmittance values for each sampled direction were then summed to calculate multidirectional light penetration index $\left({ }_{\mathrm{m}} \mathrm{LPI}\right)$ in a $1-\mathrm{m}^{3}$ voxel space on a 2-m resolution grid at $1.5 \mathrm{~m}$ above ground.

All the computations required to compute the volume-based light penetration index were conducted with the AMAPvox software. Documentation and software can be accessed at https:// amap-dev.cirad.fr/projects/voxelidar and the source code can be found at https://github.com/AMAP-dev/AMAPVox.git.

\subsection{Vertical light penetration index}

As an alternative to ${ }_{\mathrm{m}} \mathrm{LPI}$, we derived a simpler quantification of canopy transmittance called vertical light penetration index ( $\left.{ }_{v} \mathrm{LPI}\right)$ from the LiDAR data. It approximates the probability for a ray to reach the ground, and it was calculated as the number of ground LiDAR echoes divided by the total number of LiDAR echoes in a column of $5 \times 5 \mathrm{~m}^{2}$ section (Bode et al. 2014). Point counts were performed with the LASgrid tool of LAStools (Insenburg) and weighted as described above. To compensate for the effect of lateral shading and lack of ground points, data were smoothed assigning the average values of an 8-cell 2D Moore neighbourhood to the central cell.

\subsection{Ground measurement of the micro-environment}

Environmental sensors were established at 50 locations within the Nouragues Station in December 2013, and they were operated continuously until June 2015. Some sensors malfunctioned, and data from 47 locations were retained for the present study. Two sensors were coupled at each location (see Fig. 1). The first sensor measured light and temperature (HOBO Pendant UA-002-64). It was mounted horizontally at the top of a $1-\mathrm{m}$ pod, to avoid disturbance caused by understory animals and to provide light level at a reference height above the ground vegetation. The second sensor measured temperature and relative air humidity (HOBO U23-001), and it was mounted immediately below the temperature/light sensor. Measurements were logged at 15-min intervals. Temperature measurements were obtained from both sensors, and they are reported at $0.5^{\circ} \mathrm{C}$ accuracy, according to manufacturer's specifications. To control these values, we compared the two recordings and found that the median percent difference was of $0.41 \%$ (95\% confidence interval $(0.05$, 2.92)). This represents a mean difference of $0.08{ }^{\circ} \mathrm{C}(95 \%$ confidence interval $(0.01,0.74))$. Relative humidity was reported with a $2.5 \%$ absolute accuracy.

The HOBO UA-002 light sensor is based on silicon photocells. The technology and the bandwidth of the HOBO UA002 is similar to that of the LI-COR LI-200SA Pyranometer Sensor with a 150-1200-nm wavelength range. Ross and Sulev (2000) compared the LI-200SA data with the more accurate light irradiance measurements obtained by the LICOR LI-190SA Quantum Sensor, an accurate silicon photodiode covered with a visible bandpass interference filter and a coloured glass filter. They found that the LI-200SA was underestimating light irradiance by up to $20 \%$ in high-LAI forests (including reference data from a rainforest understory). This is due to the narrower wavelength bandpass of the silicon photodiode. Thus, the HOBO sensors might underestimate the energy in the solar radiation spectrum at high-LAI condition. Yet, these sensors still provide useful information when it comes to measuring the long-term light variability at many 
Table 1 Linear relations expressing measured environmental variables as a function of ${ }_{\mathrm{m}} \mathrm{LPI}$

\begin{tabular}{lrllll}
\hline Measured variable & \multicolumn{1}{c}{ Intercept } & \multicolumn{1}{l}{ slope } & RSE & Adjusted $R^{2}$ & LOO MSE \\
\hline Feild LPI (\%) & $3.9 \pm 0.6$ & $0.84 \pm 0.12$ & 2.0 & 0.51 & $4.3 \times 10^{-2}$ \\
Mean relative humidity $(\%)$ & $99.5 \pm 0.4$ & $-22.7 \pm 8.4$ & 1.17 & 0.15 & 1.8 \\
Minimal elative humidity $(\%)$ & $98.1 \pm 1.4$ & $-97.4 \pm 27$ & 3.815 & 0.25 & 19.6 \\
Maximal temperature $\left({ }^{\circ} \mathrm{C}\right)$ & $26.0 \pm 0.2$ & $22.8 \pm 3.6$ & 0.513 & 0.51 & 0.37 \\
\hline
\end{tabular}

Values are given as mean \pm standard deviation

LOO MSE leave-one-out mean square error points in a natural ecosystem. Long et al. (2012) compared the outputs of a HOBO UA-002 with a LI-193SA PAR radiation sensor in a light chamber experiment, and they showed that, while less precise, the output of the HOBO sensor could be related to the LI-COR-measured PAR value. Their primary focus was to assess the light in underwater environments, so it is difficult to directly use their calibration for our purpose.

Because of the above limitations of published calibrations, we performed an independent calibration of the HOBO UA-002 sensor. We set a HOBO UA-002 a few centimeters away from a Hukseflux SR11 pyranometer, both placed in full sunlight at our research station. The Hukseflux SR11 has a 285-3000 spectral range and $\operatorname{logs}$ the data in watts per square metre. Both sensors were logged at $1 \mathrm{~min}$ temporal resolution. We found that the light intensity ( $I$ in lux) measured from the HOBO UA-002 ( in lux) could be related to the net solar irradiance $\left(R\right.$ in $\left.\mathrm{W} \mathrm{m}^{-2}\right)$ measured by the SR11 through a second-order polynomial regression. To reduce the discrepancy due to slight difference in the time of measurement, we smoothed the data with a 3-min moving window. We obtained the relation:

$R=5.1510^{-3} \times I-4.5510^{-9} \times I^{2}$

The relation was highly significant $(p<0.001, d f=5790)$ and accurate (RMSE, $33.2 \mathrm{~W} \mathrm{~m}^{-2}$ ). We used this conversion to report all irradiance values in watts per square metre (see also Appendix 1).

The r.sun module (Hofierka et al. 2002) coded in GRASS 7.0 (GRASS Development Team 2012) was used to simulate the expected irradiance on the ground in absence of trees. This module accounts for the solar position, atmospheric parameters and a DEM complemented with values of slope and aspect at each position to compute the instantaneous incoming direct and diffuse radiation or time-integrated values. We ran
Fig. 2 Predicted microenvironment over the area of interest. All maps have a resolution of $2 \mathrm{~m}$. a Canopy height is shown by map colours and $10-\mathrm{m}$-spaced elevation lines are shown. $\mathbf{b}_{\mathrm{m}}$ LPI at $1.5 \mathrm{~m}$ above the ground. c Average maximal temperature over the year modelled using ${ }_{\mathrm{m}} \mathrm{LPI}$ at $1.5 \mathrm{~m}$ above the ground. d Average minimal relative humidity over the year at $1.5 \mathrm{~m}$ above the ground modelled using ${ }_{\mathrm{m}} \mathrm{LPI}$ and topography (adjusted $R^{2}=0.53$; $\mathrm{RSE}=3.34$ on $33 \mathrm{ddl} ; p<0.001$; $\mathrm{LOO} \mathrm{MSE}=1.37 \%$ )
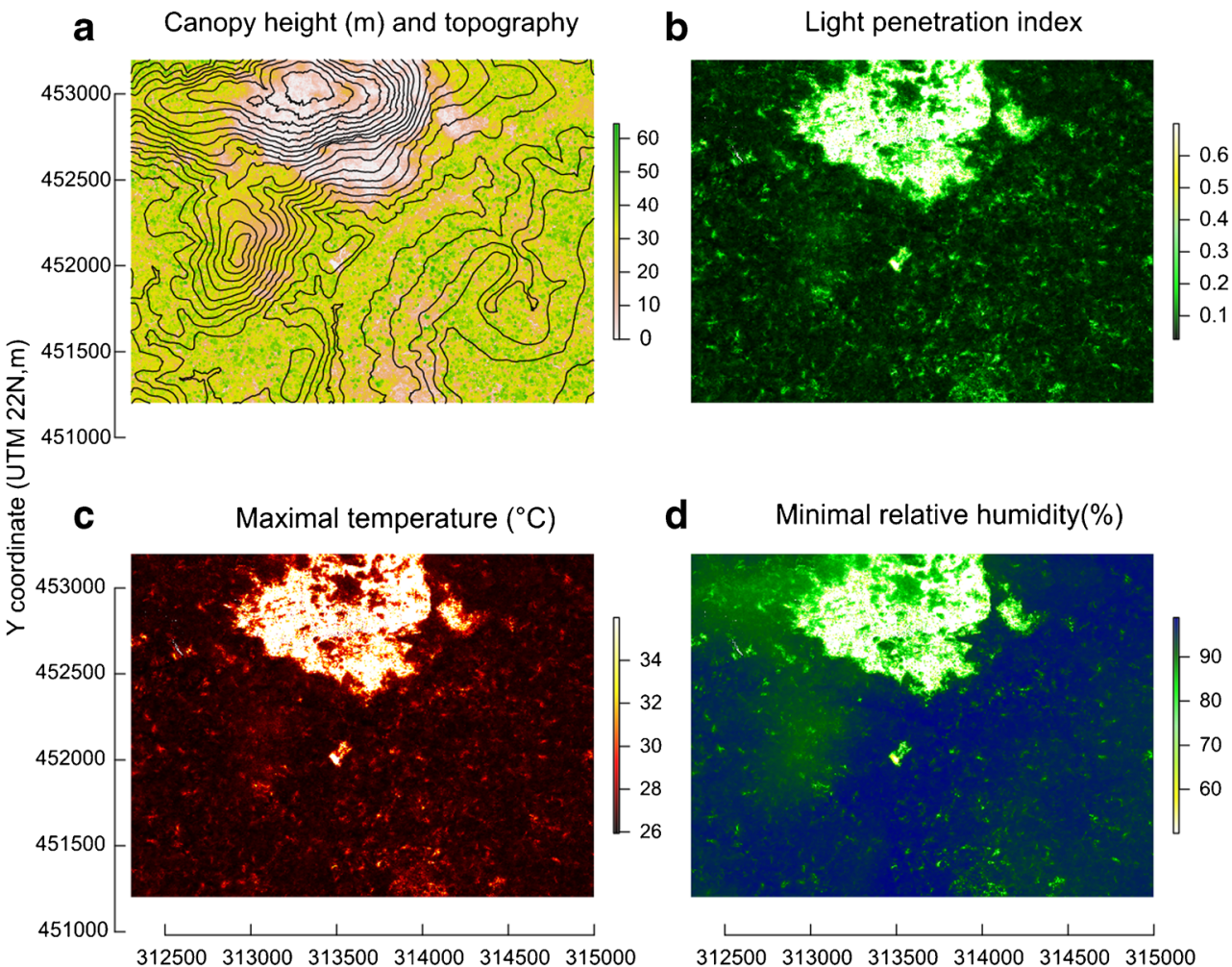

$X$ coordinate (UTM 22N,m) 
Fig. 3 Plant area density profile within the canopy. Values of PAD at a resolution of $1 \mathrm{~m}$ were averaged at every height in $225 \mathrm{~m}^{2}$ windows around 30 randomly selected positions in each forest type. Black lines represent mean values, and grey lines are the standard deviations

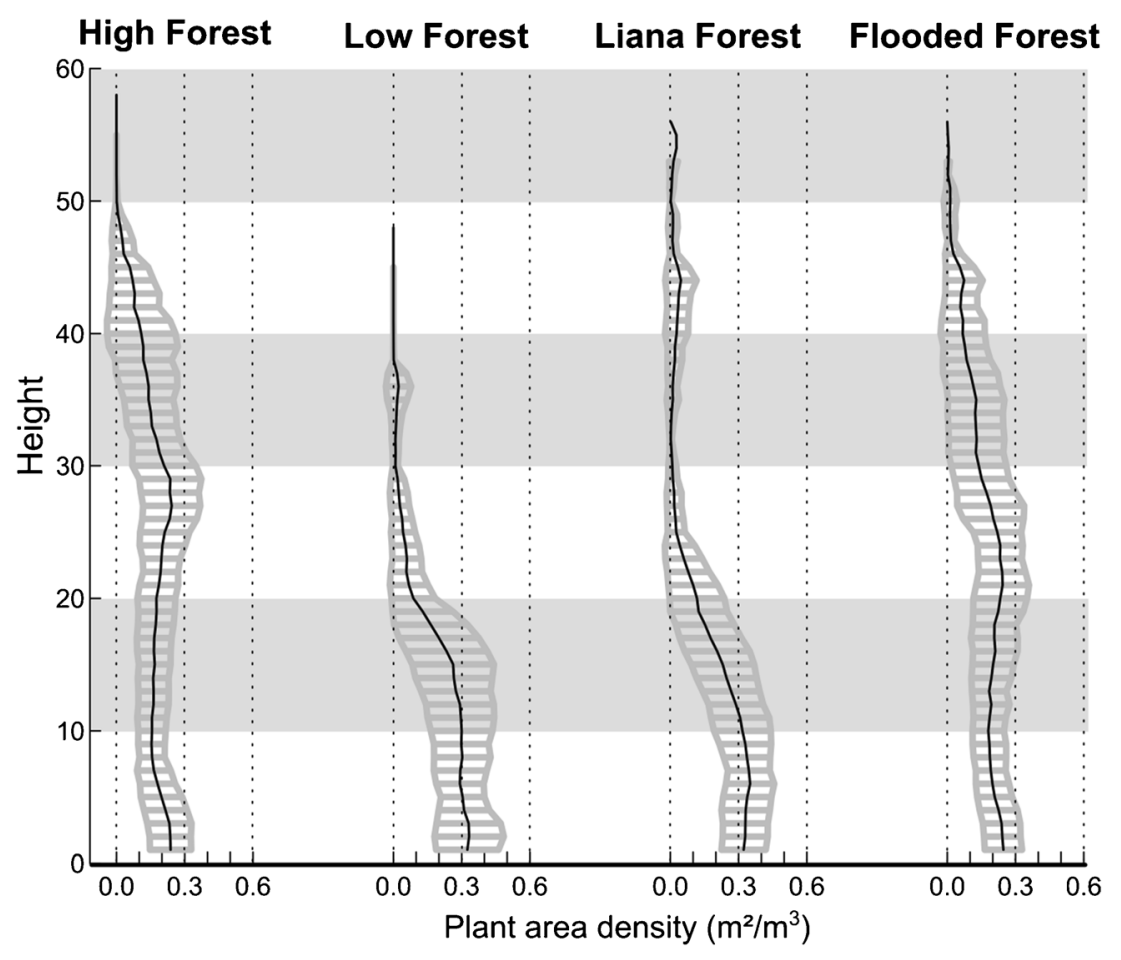

this function every day in 2014 to calculate the average daily top-of-canopy solar irradiance. For these calculations, atmospheric turbidity was assumed constant over each month and set according to Remund et al. (2003). To correct the modelled irradiance for average cloudiness, which is not explicitly modelled, we compared the model predictions against the values measured by the meteorological station. The difference between modelled and observed was assumed to be due to the monthly average cloudiness. The ratio of irradiance measured in the understory divided by the (predicted) top-of-canopy
Fig. 4 Example of a gap in the high-canopy forest. In every panel, solid lines represent values averaged every meter along a 10 m-wide and 100-m-long transect. Dashed lines represent the mean \pm 1 standard deviation. Vertical grey dashed lines represent the limits of a gap defined following Brokaw definition (canopy below $2 \mathrm{~m}$, area over $20 \mathrm{~m}^{2}$ ). a Top-of-canopy height; $\mathbf{b}$ average minimal relative humidity over the year at $1.5 \mathrm{~m}$ above the ground modelled using ${ }_{\mathrm{m}}$ LPI and topography; $\mathbf{c}$ average maximal temperature at $1.5 \mathrm{~m}$ above the ground modelled using ${ }_{\mathrm{m}}$ LPI; $\mathbf{d}_{\mathrm{m}}$ LPI at $1.5 \mathrm{~m}$ above the ground a Canopy height (m)

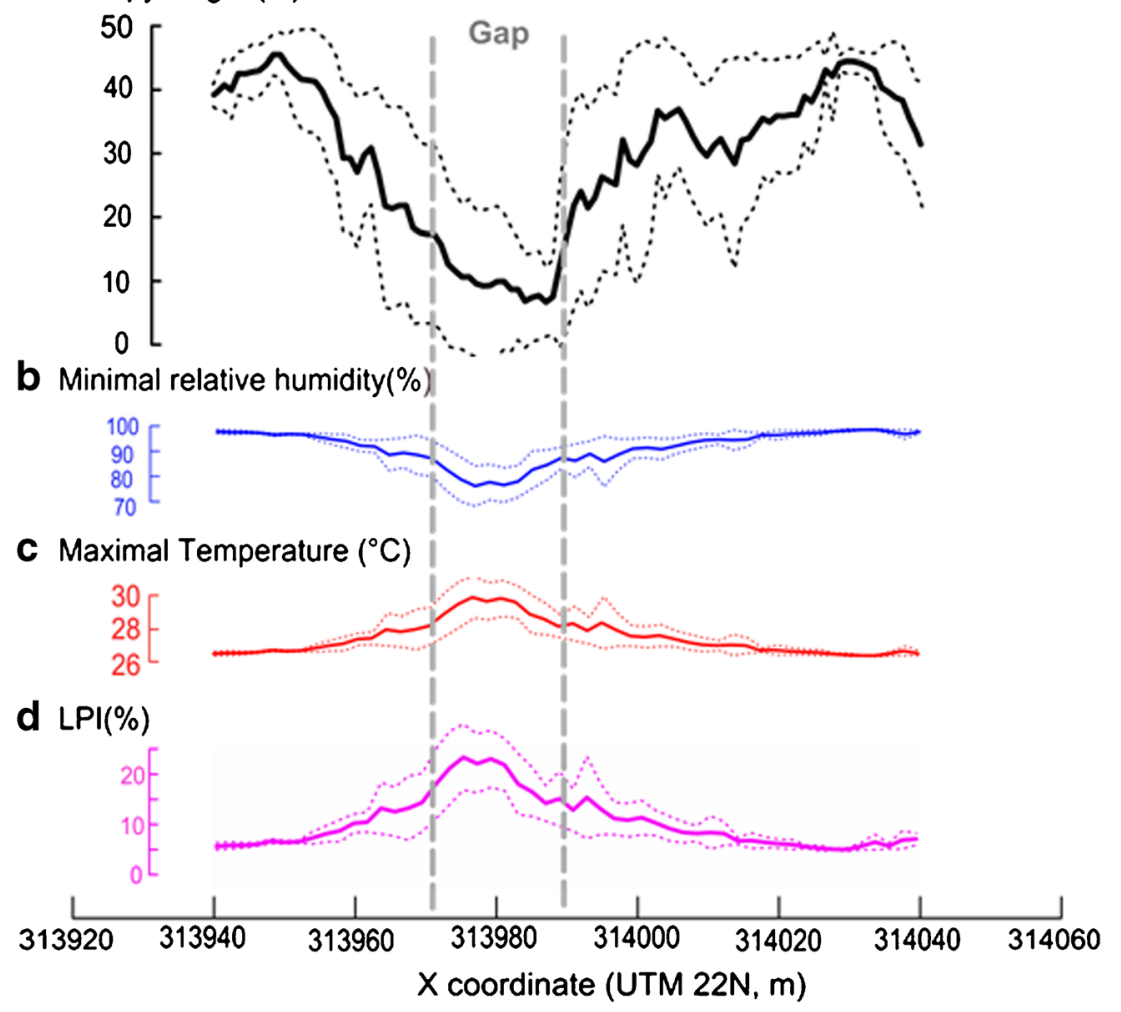


irradiance was computed daily, defining the ground-based (field) light penetration index $\left(\right.$ field $_{\text {LPI). }}$

\subsection{Statistical analyses}

Model validation was assessed by comparing modelled LPI to field data. Values of the two modelled LPI values $\left(_{v}\right.$ LPI and ${ }_{\mathrm{m}} \mathrm{LPI}$ ) were computed for the entire area of interest and extracted at the sensor positions. Positional error of the sensors was assumed to follow a normal distribution centred on 0 in $X$ and $Y$ coordinates and with a standard deviation independently assessed based on four GPS positioning recorded at more than 4-day intervals for each sensor. Modelled LPI values were extracted for 1000 random choices of position in the distribution of coordinates around the position of each sensor and were used to compute the average and standard deviation due to positioning error of modelled LPI.

To assess the ability of metrics derived from LiDAR to estimate ground-level micro-environmental variables, we tested bivariate correlations between yearly average field LPI, daily minimal relative humidity, average relative humidity or daily maximal temperature on the one hand, and modelled LPI on the other hand. We used both ordinary least square regressions and a method of parameters estimation which takes into account errors in measurement of both variables (Deming regression, see Linnet 1993; Glaister 2001). Leave-one-out cross-validation (LOOC) was performed on these relations and mean square error of prediction (MSE) was computed.

Table 2 Variation of mean radiant energy, mean temperature and mean relative humidity between dry and rainy season

\begin{tabular}{|c|c|c|}
\hline & High-canopy forest & Clearing \\
\hline \multicolumn{3}{|c|}{ Daily energy $\left(\mathrm{Wh} \mathrm{m}^{-2}\right)$} \\
\hline Dry season & $151 \pm 14$ & $4366 \pm 148$ \\
\hline Rainy season & $114 \pm 10$ & $3711 \pm 71$ \\
\hline Differences & $32 \% * * *$ & $18 \% * *$ \\
\hline \multicolumn{3}{|l|}{ Temperature $\left({ }^{\circ} \mathrm{C}\right)$} \\
\hline Dry season & $24.4 \pm 0.1$ & $29.9 \pm 0.1$ \\
\hline Rainy season & $23.9 \pm 0.1$ & $24.4 \pm 0$ \\
\hline Differences & $2.03 \% * * *$ & $1.88 \% * * *$ \\
\hline \multicolumn{3}{|c|}{ Relative humidity (\%) } \\
\hline Dry season & $97.2 \pm 0.5$ & $92.3 \pm 0.7$ \\
\hline Rainy season & $99.1 \pm 0.2$ & $94.8 \pm 0.3$ \\
\hline Differences & $-1.9 \% * * *$ & $-2.7 \% * * *$ \\
\hline$N$ & 27 & 1 \\
\hline
\end{tabular}

Differences are indicated as percentage of rainy season radiant energy. Comparisons were made per forest type between rainy season and dry season values. Statistical significance was assessed by Wilcoxon test. Values are given as mean \pm standard deviation

'-' not significant

$* * p<0.01 ; * * * p<0.001$, levels of significance

\section{Results}

\subsection{Modelling of micro-environmental condition}

${ }_{\mathrm{m}}$ LPI was a slightly better descriptor of ${ }_{\text {field }}$ LPI than ${ }_{\mathrm{v}} \mathrm{LPI}$ (adjusted $R^{2}=0.51$, MSE $=4.3 \times 10^{-2} \%$ for ${ }_{\mathrm{m}} \mathrm{LPI}$ versus 0.47 , MSE $=4.5 \times 10^{-2} \%$ for ${ }_{v}$ LPI; Table 1$)$. The use of Deming regression yielded similar results (Table S3 in Online resources).

Annual average daily maximal temperature was positively related to ${ }_{m} \mathrm{LPI}\left(R^{2}=0.51, \mathrm{MSE}=0.37{ }^{\circ} \mathrm{C}\right.$; Table 1$)$. The mean annual value of daily average and minimal relative humidity were both negatively related to ${ }_{m} \mathrm{LPI}\left(R^{2}=0.15\right.$, $\mathrm{MSE}=1.8 \%$ and $R^{2}=0.25, \mathrm{MSE}=19.6 \%$, respectively; Table 1). Including topography improved the prediction of mean relative humidity $\left(R^{2}=0.39\right.$, MSE $\left.=1.37 \%\right)$ and minimal relative humidity $\left(R^{2}=0.52, \mathrm{MSE}=12.8 \%\right)$ but had no effect on the other predicted variables.

\subsection{Spatial variability of the micro-environment}

Maps of light availability, maximal temperature and minimal relative humidity were built from ${ }_{\mathrm{m}} \mathrm{LPI}$ (and topography for humidity) through models described above (Fig. 2). The prediction error on these maps is assumed to be close to the square root of the leave-one-out mean square error $\left(0.21 \%\right.$ for LPI, $0.6{ }^{\circ} \mathrm{C}$ for maximal temperature and $3.58 \%$ for minimal humidity). Micro-environmental conditions differed clearly between high-canopy forest (mean ${ }_{\mathrm{m}} \mathrm{LPI}, 5.7 \pm 1.1 \%$; maximal temperature, $26.5 \pm 0.2{ }^{\circ} \mathrm{C}$; minimal relative humidity, $98.3 \pm 1 \%$ ) and low-canopy forest (mean ${ }_{\mathrm{m}} \mathrm{LPI}, 11.8 \pm 7.6 \%$; maximal temperature, $27.7 \pm 1.5{ }^{\circ} \mathrm{C}$; minimal relative humidity, $93 \pm 6.7 \%$; Appendix 2). Micro-environmental variation at ground level was associated with difference in the vertical profiles of vegetation density derived from lidar data (Fig. 3).

Within forest type, ${ }_{\mathrm{m}}$ LPI was on average 4.3 times higher in canopy gaps regardless of their size than in closed forest $(25.9 \pm 0.3 \%$ versus $6.1 \pm 0.01 \%)$. ${ }_{\mathrm{m}}$ LPI was positively related to gap area (slope, $0.2 \% \mathrm{~m}^{-2}$; adjusted $R^{2}, 0.15, p<0.001$ ). Average daily maximal temperature was also higher $\left(30.5 \pm 0.07{ }^{\circ} \mathrm{C}\right.$ versus $\left.26.6 \pm 0.002{ }^{\circ} \mathrm{C}\right)$ and minimal and mean relative humidity were both lower in canopy gaps (73.1 $\pm 0.4 \%$ versus $97.2 \pm 0.01 \%$ and $98.4 \pm 0.02 \%$ versus $100 \%$ ). These variations were still noticeable within ca. $20 \mathrm{~m}$ around the gaps (Fig. 4; Appendix 2).

\subsection{Variability of the micro-environment between dry and rainy season}

Using ground sensors, we quantified the intra-annual variability of the micro-environment. Light availability was ca. $18 \%$ higher during the dry season than during the wet season in the open area while it was $32 \%$ higher in the tall forest (Table 2). Temperature was $1.9 \%$ higher in the clearing and $2.0 \%$ higher 
in the tall forest. Finally, during the dry season, relative humidity was $2.7 \%$ lower in the clearing and only $1.9 \%$ lower in the tall forest (Table 2; Appendix 3).

\section{Discussion}

We modelled micro-environmental conditions in the forest understory over large area using LiDAR data. Most previous studies were based on LAI and gap fraction estimation and considered only vertical light fluxes when modelling light environment in tropical forest understory (Stark et al. 2012, 2015; Heiskanen et al. 2015). The multidirectional method presented here $\left({ }_{m}\right.$ LPI) represents a significant advance over these previous methods. Moreover, Stark et al. $(2012,2015)$ did not ground truth the results with field measurements. We did it in our study, and the irradiance values found in the understory of less than 5\% of full sunlight are commensurate to, albeit slightly higher than, previously published observations (Chazdon and Fetcher 1984; Bongers et al. 2001).

Our study confirms the existence of consistent microenvironmental differences in the understory of different forest types. This suggests that distinction of forest types is meaningful because differences in micro-environmental conditions will potentially impact forest dynamics, ecosystem processes and composition in habitat.

Light availability assessments have direct implications for the study of plant demography because ambient light, and notably its diffuse component, has been shown to impact directly plant demographic rates (Scanga 2014) and plant germination (Baskin and Baskin 2001). Light availability is also essential for carbon assimilation and plant growth (Nicotra et al. 1999; Dalling and Hubbell 2002; Montgomery and Chazdon 2002). Ground-level light maps derived from LiDAR could be thus of great interest in providing better predictive underpinnings for the demographic studies of understory plants (Ackerly and Bazzaz 1995; Baraloto and Goldberg 2004 Laurans M et al 2012; Vincent G et al 2011). Species composition and vegetation abundance in the understory also vary with differences in micro-environmental conditions (e.g. Dirzo et al. 1992; Svenning 2001). In the lianainfested forest for instance, understory vegetation is extremely dense, which could result from the higher light availability. The 3D model gives the opportunity to test such relations at every level of the canopy for instance in the study of epiphytes which biomass and diversity were shown to be related to air humidity in our study zone (Gehrig-Downie et al. 2011; Obregon et al. 2011). Prediction of micro-climatic conditions can also serve to define habitat for animals (Goetz et al. 2010).

Canopy gaps are important loci of forest regeneration (Hubbell et al. 1999; Svenning 2001). We here confirm that even small gaps receive considerably more light than the gap surrounding (less than $20 \mathrm{~m}$ of a gap edge) are also warmer and receive more light than average understory. Temperature is directly linked with metabolic processes, such as heterotrophic soil respiration, and it thus alters biogeochemical processes (Salinas et al. 2011), notably through modifications of the dynamics of microbial populations (Hudson 1968). The volume-based model gives the opportunity to approximate micro-environmental variables within the canopy at the landscape scale. This might help improve predictions of photosynthesis levels, gas fluxes and other physiological processes in tall structurally complex forests. Conversely, relative air moisture was lower in canopy gaps and around, which may result in a lowered soil moisture and then lower seed survival and germination rates (Marthews et al. 2008) as well as lower microbial populations (Hudson 1968).

Our estimations of the transmittance of the different forest canopies are related with the plant area index (PAI). If we assume similar proportion of wood and leaves in the PAI across forest types, it appears that LAI is lower in the low forest than in the liana-infested forest and the flooded forest, where it is lower than in the high-canopy forest. The lower LAI in liana-infested compared with high-canopy forests has also been demonstrated in a previous study at a smaller scale (Tymen et al. 2016).

\subsection{Limitations and sources of error}

Part of the unexplained variation in micro-environmental conditions is due to inherent issues in the model, but another part is only due to noise in the experimental data.

First, in the irradiance model itself, we neglected possible anisotropy of canopy transmittance. This is equivalent to assuming a spherical leaf distribution in the canopy (Monteith and Unsworth 2013) while neglecting the contribution of woody components to light interception. According to Heiskanen et al. (2015) and data from terrestrial laser scanning collected in another forest site in French Guiana (Vincent et al. 2015), leaf angle distribution in tropical forests is not spherical and transmittance is then anisotropic. Hence, the PAI profiles given here should be considered with caution. They provide a mean of comparing forest vegetation structure through normalised profiles. A true PAI should consider possible transmittance anisotropy during inversion. Obtaining a LAI estimate would further require separating foliage from wood. Clumping of canopy elements at a smaller scale than $1 \mathrm{~m}$ is also neglected in our model. This increases light availability heterogeneity in the understory and leads to underestimation of plant area index. Further issues are related to experimental conditions and simplifying assumptions

On average, the coefficient of variation of ${ }_{\text {field }} \mathrm{LPI}$ during the year was $47 \%$. This variation is partly due to phenological 
variation of canopy such as leaf loss not considered in our model. Short-scale local variations in atmospheric conditions were not corrected in our estimation of the top-of-canopy light when undetected by the meteorological station (for instance small cloud shadows at sensor position), The above mentioned issues contribute to the uncertainty affecting field LPI, the response variable of the model (Table 2).

Moreover, linking measured to modelled values of LPI is subject to errors due to inaccurate sensor positioning by GPS. Error varies between sensors, depending on local conditions, canopy density in particular. Considering that positioning error is normally distributed, the coefficient of variation for ${ }_{\mathrm{m}}$ LPI was found to be on average $24 \%$. Our evaluation of the goodness of prediction of our model is then probably underestimated. A better positioning of field sensor could demonstrate that fact.

Another issue is that sensors used in this study do not directly measure radiant energy (in $\mathrm{W} \mathrm{m}^{-2}$ ) and do not give information on the radiation spectrum. The transformation performed to provide values of radiant energy may not hold in the understory because the light spectrum is altered (Lee 1987; Endler 1993; Long et al. 2012). However, a significant portion of the light contributing to our measures may pass as sunflecks through small openings in the canopy (Bone et al. 1985 ) and is not altered by canopy filtering.

\section{Conclusion}

In this study, using LiDAR data and a simple light transmission model, we were able to predict more than $50 \%$ of the observed spatio-temporal variation in light availability at ground level in a tropical forest. This suggests that our model can be useful in various ecological studies in tropical forest understory.

A substantial part of the unexplained variation in understory light regime comes from identified sources of error that can be reduced drastically based on the present study and new measurements. Moreover, terrestrial LiDAR scanner can alleviate most of the limitations encountered in our study. Low sampling of the understory due to insufficient aerial LiDAR penetration can be overcome by terrestrial LiDAR, which allows a much denser sampling pattern. It may also ultimately provide robust leaf area index estimates as it has the potential to separate leaf from non-leaf material (Raumonen et al. 2013; Calders et al. 2015; Newnham et al. 2015) and to provide a more accurate description of the spatial arrangement of the foliage (clumping and orientation).

Acknowledgements We thank Lætitia Proux, Guillaume Robert and Guilhem Sommeria-Klein for their help collecting data on the field. We thank Maxime Réjou-Méchain for his highly constructive criticisms on the manuscript.
Compliance with ethical standards

Funding We gratefully acknowledge financial support from CNES (TOSCA programme), and from 'Investissement d'Avenir' grants managed by Agence Nationale de la Recherche (CEBA, ref. ANR-10LABX-25-01; TULIP: ANR-10-LABX-0041; ANAEE-France: ANR11-INBS-0001)

Conflict of interest The authors declare no conflict of interest.

\section{Appendix 1: Comparison between the HOBO UA-002 and the Hukseflux SR11}

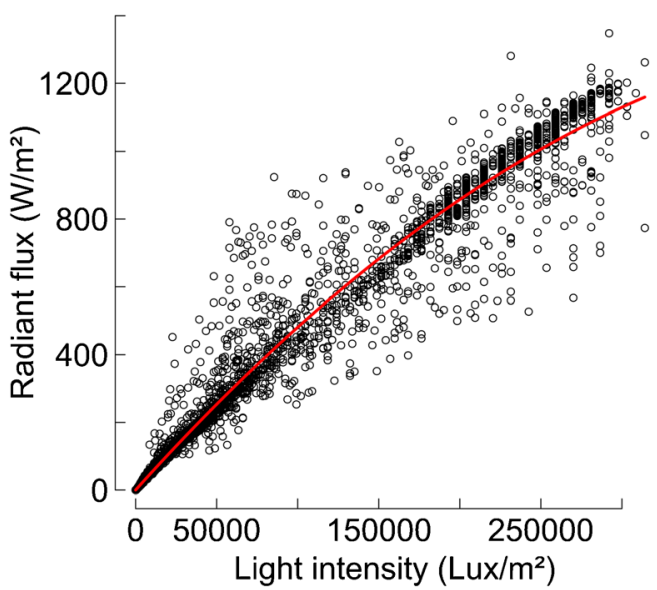

Fig. 5 Comparison of daily HOBO outputs in full sunlight and SNR11 pyranometer outputs. Measures were compared every $5 \mathrm{~mm}$ for 20 days between 9 and 29 of September $2015(n=5792)$. We computed the mean daily output of one HOBO sensor placed in full sunlight (H35, in lux) and also the output from a pyranometer also placed in full sunlight (Hukseflux $\mathrm{SR} 11$ in $\mathrm{W} \mathrm{m}^{-2}$ ). The SR11 sensor was logged at 1-min temporal resolution. We found that the mean light intensity (in lux) could be related to the net solar irradiance through a second-order polynomial regression $\left(R^{2}, 0.99, p<0.001\right)$ : irradiance $\left(\mathrm{W} \mathrm{m}^{-2}\right)=8.7 \times 10^{-3} \times$ $\mathrm{HOBO}-7.3 \times 10^{-8} \times(\mathrm{HOBO})^{2}$

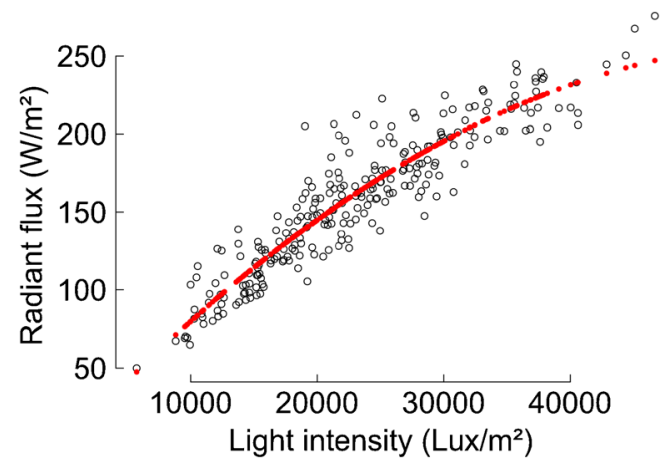

Fig. 6 Comparison of daily mean HOBO outputs in full sunlight and daily mean SR11 pyranometer outputs. Measures were compared for most of year $2014(n=256$ days). The most sunlit days had peak net irradiance values above $1000 \mathrm{~W} \mathrm{~m}^{-2}$ 


\section{Appendix 2: Spatial variability of micro-environment}

Table 3 Variability of predictions with forest types

\begin{tabular}{lccrr}
\hline & High forest & Low forest & Liana forest & Flooded forest \\
\hline LPI $(\%)$ & $5.7 \pm 1.1$ & $11.8 \pm 7.6$ & $9.0 \pm 5.0$ & $6.9 \pm 2.9$ \\
Daily radiant energy $\left(\mathrm{Wh} \mathrm{m}^{-2}\right.$ ) & $15.6 \pm 2.1$ & $27.3 \pm 14.7$ & $21.8 \pm 9.6$ & $17.9 \pm 5.7$ \\
Daily maximal temperature $\left({ }^{\circ} \mathrm{C}\right)$ & $26.5 \pm 0.2$ & $27.7 \pm 1.5$ & $27.2 \pm 1.0$ & $26.8 \pm 0.6$ \\
Daily minimal relative humidity (\%) & $98.3 \pm 1.0$ & $93.0 \pm 6.7$ & $95.5 \pm 4.5$ & $97.3 \pm 2.6$ \\
Daily average relative humidity $(\%)$ & $100 \pm 0.1$ & $99.5 \pm 0.6$ & $99.7 \pm 0.4$ & $99.9 \pm 0.2$ \\
\hline
\end{tabular}

Modelled values of ${ }_{\mathrm{m}} \mathrm{LPI}$, daily radiant energy, maximal temperature and minimal and mean relative humidity averaged over the year were extracted at 50 positions randomly chosen within the different forest types (mean $\pm \mathrm{SD}$ )
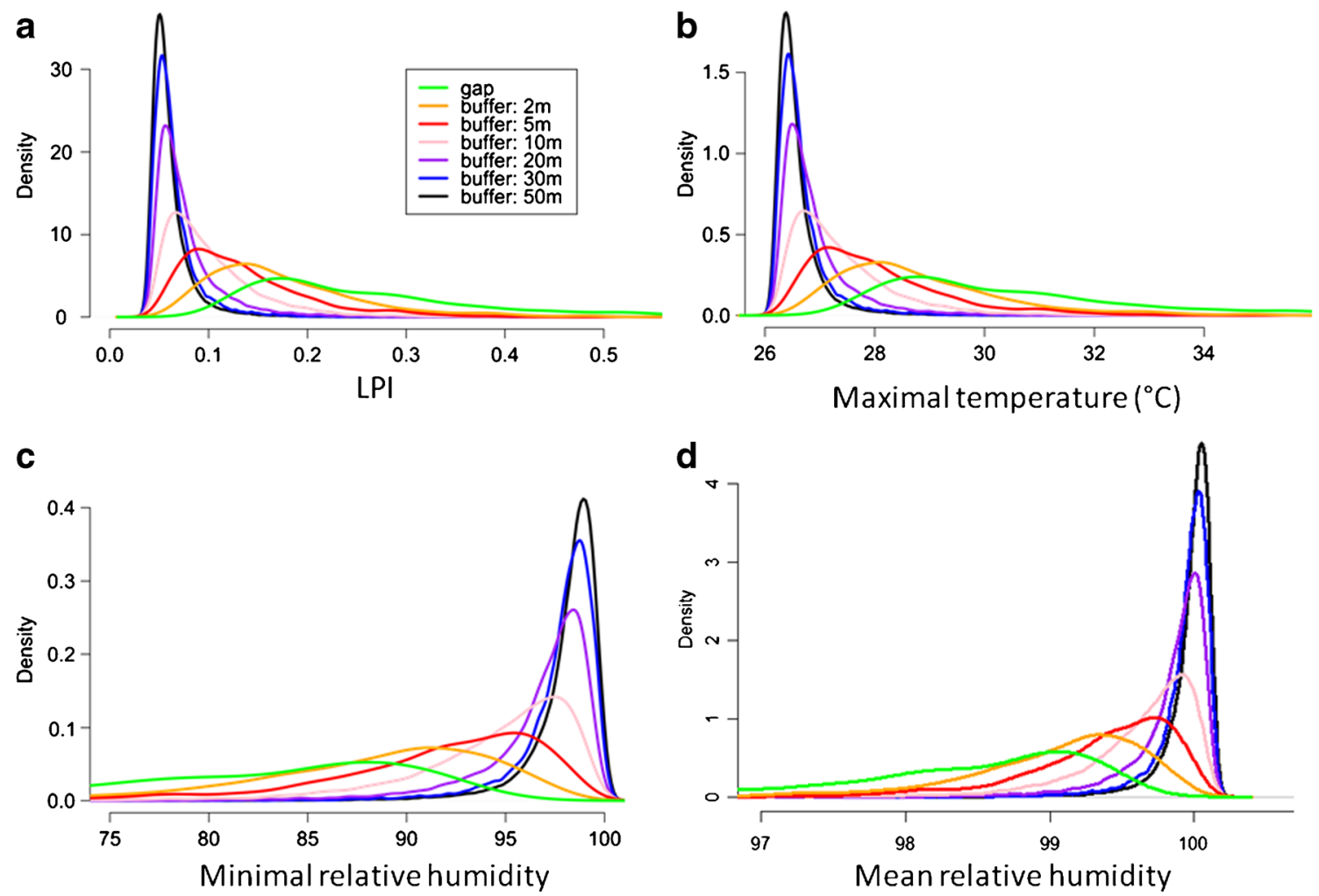

Fig. 7 Micro-environment in canopy gaps and in concentric buffers around canopy gaps. Gaps were defined following Brokaw's (1982) definition as area larger than $20 \mathrm{~m}^{2}$ with a canopy height lower than $2 \mathrm{~m}$. On the zone of interest, 81 gaps were detected in every forest

types. Micro-environmental conditions in these gaps were compared with condition in buffer around them regardless of the type of vegetation in these buffers 


\section{Appendix 3: Temporal variability in micro-environmental conditions}

Table 4 Variation of measured radiant energy, temperature and relative humidity between dry and rainy season

\begin{tabular}{llllll}
\hline & High forest & Low forest & Liana forest & Flooded forest & Clearing \\
\hline Daily energy $\left(\mathrm{Wh} \mathrm{m}^{-2}\right)$ & & & & \\
Dry season & $151 \pm 14$ & $236 \pm 51$ & $136 \pm 24$ & $159 \pm 39$ & $4366 \pm 148$ \\
Rainy season & $114 \pm 10$ & $190 \pm 43$ & $108 \pm 15$ & $123 \pm 42$ & $3711 \pm 71$ \\
Difference & 37 & 45 & 28 & 37 & 655 \\
Difference & $32 \% * * *$ & $24 \% * * *$ & $26 \% * * *$ & $30 \% * * *$ & $18 \% * *$ \\
Temperature $\left({ }^{\circ} \mathrm{C}\right)$ & & & & \\
Dry season & $24.4 \pm 0.1$ & $24.6 \pm 0.3$ & $24.3 \pm 0.1$ & $24.3 \pm 0.1$ & $24.9 \pm 0.1$ \\
Rainy season & $23.9 \pm 0.1$ & $23.9 \pm 0.2$ & $24 \pm 0.1$ & $24 \pm 0.1$ & $24.4 \pm 0$ \\
Difference & 0.5 & 0.7 & 0.3 & 0.3 & 0.5 \\
Difference & $2.03 \% * * *$ & $3.17 \% * * *$ & $1.58 \% * * *$ & $1.23 \% * * *$ & $1.88 \% * * *$ \\
Relative humidity $(\%)$ & & & & $92.3 \pm 0.7$ \\
Dry season & $97.2 \pm 0.5$ & $94.1 \pm 1.1$ & $97.8 \pm 1.1$ & $98.9 \pm 0.4$ & $94.8 \pm 0.3$ \\
Rainy season & $99.1 \pm 0.2$ & $98.3 \pm 0.5$ & $99.6 \pm 0.3$ & $99.9 \pm 0.1$ & 2.5 \\
Difference & 1.9 & 4.2 & 1.8 & 1 & $-2.7 \% * * *$ \\
Difference & $-1.9 \% * * *$ & $-4.3 \% * * *$ & $-1.8 \% * * *$ & $-0.9 \% * * *$ & 1 \\
$\boldsymbol{N}$ & 27 & 8 & 3 & 8 & \\
\hline
\end{tabular}

Differences are indicated as percentage of rainy season values. Comparisons were made per forest type between rainy season and dry season values. Significance was assessed by Wilcoxon test

'-' not significant

$* * p<0.01 ; * * * p<0.001$, levels of significance

\begin{tabular}{llrrrc}
\hline & & High forest & Low forest & Liana forest & Flooded forest \\
\hline Light $\left(\mathrm{W} \mathrm{m}^{-2}\right)$ & Dry season & $0-32.8$ & $0-50.4$ & $0-26.6$ & $0-34.4$ \\
& Rainy season & $0-24.7$ & $0-45.5$ & $0-19.4$ & $0-27$ \\
Temperature $\left({ }^{\circ} \mathrm{C}\right)$ & Dry season & $22.6-27.2$ & $22.5-28.6$ & $22.4-27.5$ & $22.3-27.4$ \\
& Rainy season & $22.7-25.9$ & $22.5-26.6$ & $22.6-26.1$ & $22.6-26.1$ \\
Relative humidity $(\%)$ & Dry season & $92.8-99.7$ & $81.7-99.6$ & $91.6-99.6$ & $95.3-100$ \\
& Rainy season & $97.9-99.9$ & $93.7-99.9$ & $98.2-99.8$ & $99.4-100$ \\
\hline
\end{tabular}

Values are indicated per season as follows: average of the minimal daily value - average of the maximal daily value
Table 5 Average daily ranges of variation in measured temperature and humidity in different forest types 


\section{References}

Ackerly DD, Bazzaz FA (1995) Seedling crown orientation and interception of diffuse radiation in tropical forest gaps. Ecology 76:1134 1146. doi: $10.2307 / 1940921$

Balzter H, Braun PW, Köhler W (1998) Cellular automata models for vegetation dynamics. Ecol Model 107:113-125

Baraloto C, Goldberg DE (2004) Microhabitat associations and seedling bank dynamics in a neotropical forest. Oecologia 141:701-712. doi: 10.1007/s00442-004-1691-3

Baskin CC, Baskin JM (2001) Seeds: ecology, biogeography, and evolution of dormancy and germination. Elsevier

Bode CA, Limm MP, Power ME, Finlay JC (2014) Subcanopy solar radiation model: predicting solar radiation across a heavily vegetated landscape using LiDAR and GIS solar radiation models. Remote Sens Environ 154:387-397. doi:10.1016/j.rse.2014.01.028

Bone, R. A., D. W. Lee, and J. M. Norman. 1985. "Epidermal Cells Functioning as Lenses in Leaves of Tropical Rain-Forest Shade Plants." Applied Optics 24 (10): 1408. doi:10.1364/AO.24.001408

Bongers, Frans, Peter J. van der Meer, and Marc Théry. 2001. "Scales of Ambient Light Variation.” In Nouragues, edited by Frans Bongers, Pierre Charles-Dominique, Pierre-Michel Forget, and Marc Théry, 19-30. Monographiae Biologicae 80. Springer Netherlands. http:// link.springer.com/chapter/10.1007/978-94-015-9821-7 3

Brokaw NVL (1982) The definition of treefall gap and its effect on measures of forest dynamics. Biotropica 14:158-160. doi:10.2307/ 2387750

Calders K, Schenkels T, Bartholomeus H et al (2015) Monitoring spring phenology with high temporal resolution terrestrial LiDAR measurements. Agric For Meteorol 203:158-168. doi:10.1016/j. agrformet.2015.01.009

Canham CD, Finzi AC, Pacala SW, Burbank DH (1994) Causes and consequences of resource heterogeneity in forests: interspecific variation in light transmission by canopy trees. Can J For Res 24:337349. doi:10.1139/x94-046

Capers RS, Chazdon RL (2004) Rapid assessment of understory light availability in a wet tropical forest. Agric For Meteorol 123:177185. doi:10.1016/j.agrformet.2003.12.009

Chazdon RL, Fetcher N (1984) Photosynthetic light environments in a lowland tropical rain forest in Costa Rica. J Ecol 72:553-564. doi: $10.2307 / 2260066$

Chazdon RL, Pearcy RW (1991) The importance of sunflecks for forest understory plants. Bioscience 41:760-766. doi:10.2307/ 1311725

Dalling, J. W., and S. P. Hubbell. 2002. "Seed Size, Growth Rate and Gap Microsite Conditions as Determinants of Recruitment Success for Pioneer Species.” Journal of Ecology 90 (3): 557-68. doi:10.1046/j. 1365-2745.2002.00695.x

Dauzat J, Franck N, Vaast P, et al., (2007) Using virtual plants for upscaling carbon assimilation from the leaf to the canopy level. Application to coffee agroforestry systems. In: 21st International Conference on Coffee Science, Montpellier, France, 11-15 September, 2006. Association Scientifique Internationale du Café (ASIC), pp 1037-1044

Dauzat J, Rapidel B, Berger A (2001) Simulation of leaf transpiration and sap flow in virtual plants: model description and application to a coffee plantation in Costa Rica. Agric For Meteorol 109:143-160. doi:10.1016/S0168-1923(01)00236-2

Den Dulk JA (1989) The interpretation of remote sensing: a feasibility study. Landbouwuniversiteit te Wageningen

Dirzo R, Horvitz CC, Quevedo H, Lopez MA (1992) The effects of gap size and age on the understorey herb community of a tropical Mexican rain forest. J Ecol 80:809-822. doi:10.2307/2260868

Endler JA (1993) The color of light in forests and its implications. Ecol Monogr 63:2-27. doi:10.2307/2937121
Engelbrecht BMJ, Herz HM (2001) Evaluation of different methods to estimate understorey light conditions in tropical forests. J Trop Ecol 17:207-224. doi:10.1017/S0266467401001146

Gehrig-Downie C, Obregón A, Bendix J, Gradstein SR (2011) Epiphyte biomass and canopy microclimate in the tropical lowland cloud forest of French Guiana. Biotropica 43:591-596

Glaister P (2001) 85.13 least squares revisited. Math Gaz 85:104-107. doi: $10.2307 / 3620485$

Goetz SJ, Steinberg D, Betts MG et al (2010) LiDAR remote sensing variables predict breeding habitat of a Neotropical migrant bird. Ecology 91:1569-1576. doi:10.1890/09-1670.1

GRASS Development Team (2012) Geographic Resources Analysis Support System (GRASS) Software. Open Source Geospatial Foundation Project

Heiskanen J, Korhonen L, Hietanen J, Pellikka PKE (2015) Use of airborne LiDAR for estimating canopy gap fraction and leaf area index of tropical montane forests. Int J Remote Sens 36:2569-2583. doi: $10.1080 / 01431161.2015 .1041177$

Hofierka J, Suri M, others (2002) The solar radiation model for open source GIS: implementation and applications. In: Proceedings of the Open source GIS-GRASS users conference. pp 1-19

Hubbell SP, Foster RB, O'Brien ST et al (1999) Light-gap disturbances, recruitment limitation, and tree diversity in a neotropical forest. Science 283:554-557. doi:10.1126/science.283.5401.554

Hudson HJ (1968) The ecology of fungi on plant remains above the soil. New Phytol 67:837-874. doi:10.1111/j.1469-8137.1968.tb06399.x

Insenburg M., LAStools - efficient LiDAR processing software (version 160921, academic) obtained from http://rapidlasso.com/LAStools

Laurans M, Martin O, Nicolini E, Vincent G (2012) Functional traits and their plasticity predict tropical trees regeneration niche even among species with intermediate light requirements. Journal of Ecology 100:1440-1452. doi:10.1111/j.1365-2745.2012.02007.x

Le Galliard J-F, Guarini J-M, Gaill F (2012) Sensors for ecology: towards integrated knowledge of ecosystems. CNRS-[Institut écologie et environnement]

Lee, David W. 1987. "The Spectral Distribution of Radiation in Two Neotropical Rainforests.” Biotropica 19 (2): 161-66. doi:10.2307/ 2388739

Lee H, Slatton KC, Roth BE, Cropper WP (2009) Prediction of forest canopy light interception using three-dimensional airborne LiDAR data. Int $\mathrm{J}$ Remote Sens 30:189-207. doi:10.1080/01431160802261171

Lefsky MA, Cohen WB, Parker GG, Harding DJ (2002) LiDAR remote sensing for ecosystem studies. Bioscience 52:19-30. doi:10.1641/ 0006-3568(2002)052[0019:LRSFES]2.0.CO;2

Linnet K (1993) Evaluation of regression procedures for methods comparison studies. Clin Chem 39:424-432

Long MH, Rheuban JE, Berg P, Zieman JC (2012) A comparison and correction of light intensity loggers to photosynthetically active radiation sensors. Limnol Oceanogr Methods 10:416-424. doi:10. 4319/lom.2012.10.416

Marthews TR, Burslem DFRP, Paton SR et al (2008) Soil drying in a tropical forest: three distinct environments controlled by gap size. Ecol Model 216:369-384. doi:10.1016/j.ecolmodel.2008.05.011

Monteith J, Unsworth M (2013) Principles of environmental physics: plants, animals, and the atmosphere. Academic Press

Montgomery RA, Chazdon RL (2001) Forest structure, canopy architecture, and light transmittance in tropical wet forests. Ecology 82: 2707-2718. doi:10.1890/0012-9658(2001)082[2707:FSCAAL]2. $0 . \mathrm{CO} ; 2$

Montgomery R, Chazdon R (2002) Light gradient partitioning by tropical tree seedlings in the absence of canopy gaps. Oecologia 131:165174. doi:10.1007/s00442-002-0872-1

Mücke W, Hollaus M, et al., (2011) Modelling light conditions in forests using airborne laser scanning data. 
Newnham GJ, Armston JD, Calders K et al (2015) Terrestrial laser scanning for plot-scale forest measurement. Curr For Rep 1:239-251. doi:10.1007/s40725-015-0025-5

Nicotra AB, Chazdon RL, Iriarte SVB (1999) Spatial heterogeneity of light and woody seedling regeneration in tropical wet forests. Ecology 80:1908-1926. doi:10.1890/0012-9658(1999)080[1908: SHOLAW]2.0.CO;2

Obregon A, Gehrig-Downie C, Gradstein SR et al (2011) Canopy level fog occurrence in a tropical lowland forest of French Guiana as a prerequisite for high epiphyte diversity. Agric For Meteorol 151: 290-300. doi:10.1016/j.agrformet.2010.11.003

Palomaki MB, Chazdon RL, Arroyo JP, Letcher SG (2006) Juvenile tree growth in relation to light availability in second-growth tropical rain forests. J Trop Ecol 22:223-226. doi:10.1017/S0266467405002968

Parker GG, Lefsky MA, Harding DJ (2001) Light transmittance in forest canopies determined using airborne laser altimetry and in-canopy quantum measurements. Remote Sens Environ 76:298-309. doi: 10.1016/S0034-4257(00)00211-X

Peng S, Zhao C, Xu Z (2014) Modeling spatiotemporal patterns of understory light intensity using airborne laser scanner (LiDAR). ISPRS J Photogramm Remote Sens 97:195-203. doi:10.1016/j. isprsjprs.2014.09.003

Raumonen P, Kaasalainen M, Åkerblom M et al (2013) Fast automatic precision tree models from terrestrial laser scanner data. Remote Sens 5:491-520. doi:10.3390/rs5020491

Regan BC, Julliot C, Simmen B et al (2001) Fruits, foliage and the evolution of primate colour vision. Philos Trans Biol Sci 356:229 283. doi:10.1098/rstb.2000.0773

Réjou-Méchain M, Tymen B, Blanc L et al (2015) Using repeated smallfootprint LiDAR acquisitions to infer spatial and temporal variations of a high-biomass Neotropical forest. Remote Sens Environ 169:93101. doi:10.1016/j.rse.2015.08.001

Remund J, Wald L, Lefevre M, et al (2003) Worldwide Linke turbidity information. In: ISES Solar World Congress 2003. International Solar Energy Society (ISES), Göteborg, Sweden, p 13 p

Ross J, Sulev M (2000) Sources of errors in measurements of PAR. Agric For Meteorol 100:103-125. doi:10.1016/S0168-1923(99)00144-6

Sabatier D, Prévost M-F (1990) Variations du peuplement forestier a l' echelle stationnelle: le cas de la station des Nouragues en Guyane Francaise.

Salinas N, Malhi Y, Meir P et al (2011) The sensitivity of tropical leaf litter decomposition to temperature: results from a large-scale leaf translocation experiment along an elevation gradient in Peruvian forests. New Phytol 189:967-977. doi:10.1111/j.1469-8137.2010. 03521.x

Scanga, Sara E. 2014. "Population Dynamics in Canopy Gaps: Nonlinear Response to Variable Light Regimes by an Understory Plant." Plant Ecology 215 (8): 927-35. doi:10.1007/s11258-014-0344-9
Smith AP, Hogan KP, Idol JR (1992) Spatial and temporal patterns oflLight and canopy structure in a lowland tropical moist forest. Biotropica 24:503-511. doi:10.2307/2389012

Stark SC, Enquist BJ, Saleska SR et al (2015) Linking canopy leaf area and light environments with tree size distributions to explain Amazon forest demography. Ecol Lett 18:636-645. doi:10.1111/ ele. 12440

Stark SC, Leitold V, Wu JL et al (2012) Amazon forest carbon dynamics predicted by profiles of canopy leaf area and light environment. Ecol Lett 15:1406-1414. doi:10.1111/j.1461-0248.2012.01864.x

Svenning J-C (2001) On the role of microenvironmental heterogeneity in the ecology and diversification of neotropical rain-forest palms (Arecaceae). Bot Rev 67:1-53

Tang H, Dubayah R, Swatantran A et al (2012) Retrieval of vertical LAI profiles over tropical rain forests using waveform LiDAR at La Selva, Costa Rica. Remote Sens Environ 124:242-250. doi:10. 1016/j.rse.2012.05.005

Tinoco-Ojanguren C, Pearcy RW (1995) A comparison of light quality and quantity effects on the growth and steady-state and dynamic photosynthetic characteristics of three tropical tree species. Funct Ecol 9:222-230. doi:10.2307/2390568

Tymen B, Réjou-Méchain M, Dalling JW et al (2016) Evidence for arrested succession in a liana-infested Amazonian forest. J Ecol 104:149-159. doi:10.1111/1365-2745.12504

Valladares F (2003) Light heterogeneity and plants: from ecophysiology to species coexistence and biodiversity. In: Progress in botany. Springer, Heidelberg, pp 439-471

van der Meer PJ, Bongers F (1996) Patterns of tree-fall and branch-fall in a tropical rain forest in French Guiana. J Ecol 84:19-29. doi:10. 2307/2261696

Vincent G, Molino J-F, Marescot L, Barkaoui K, Sabatier D, Freycon V, Roelens J-B (2011) The relative importance of dispersal limitation and habitat preference in shaping spatial distribution of saplings in a tropical moist forest: a case study along a combination of hydromorphic and canopy disturbance gradients. Annals of Forest Science 68: 357-370. doi:10.1007/s13595-011-0024-z

Vincent G, Antin C, Dauzat J et al (2015) Mapping plant area index of tropical forest by LiDAR: calibrating ALS with TLS. Proc SilviLaser 2015:146-148

Wagner W, Ullrich A, Ducic V et al (2006) Gaussian decomposition and calibration of a novel small-footprint full-waveform digitising airborne laser scanner. ISPRS J Photogramm Remote Sens 60:100 112. doi:10.1016/j.isprsjprs.2005.12.001

Willis CG, Baskin CC, Baskin JM et al (2014) The evolution of seed dormancy: environmental cues, evolutionary hubs, and diversification of the seed plants. New Phytol 203:300-309. doi:10.1111/nph.12782 